\title{
THE IMPACTOF HOLY KAABA CUBIC SHAPE ON THE INCORPOREAL SPACE
}

| Received May 4th, 2018 | Accepted July 27th, 2018 | Available Online December 15th, 2018 DOI: http://dx. doi. org/10.18860/jia.v5i2.5040

\section{Hiba Alhawasli}

Department of Architecture Engineering

Tarbiat Modares University, Tehran, Iran alhawaslih@gmail.com

\section{Mohammad Reza Bemanian}

Department of Architecture Engineering

Tarbiat Modares University, Tehran, Iran

Bemanian@modares.ac.ir

\begin{abstract}
The Holy Kaaba is the house of God; the home of greatness secrets, wisdom and divine beauty, which is reflected in all his creatures. This study aims to find the role of the shape of holy Kaaba in producing such kind of spaces and discovering the characteristics possessed by its form which has an impact in creating such incorporeal space. In this study, scientific articles and research were used to achieve the rules of research theory with taking into account considering the position of Islamic theoretical and practical wisdom. In the process of creating works of art, architecture and joint issues with urbanization, and by using the rational method to find out, in the end, the study shows the space of Holy Kaaba is a sign of divine glory from visualization and embodiment material. The nature veil in this space shines the divine light in human conscience. Human perception of space is related to his knowledge of himself and the world. Human in the use of space is approaches to percepts the true meaning of it. His intellectual device with a personal intelligent device that space is created will be compatible. The holy Kaaba spiritual space makes human feel poverty in front of the richness of the homeowner. Also, a sense of peace and sustainability due to a connection felt with God and seeking to reach the perfection that has been formed by the cube-shaped of holy Kaaba. .
\end{abstract}

\section{KEYWORDS:}

Holy Kaaba; the geometry of Kaaba; cubic shape of Kaaba; spiritual space; squaring the circle

\section{INTRODUCTION}

Islam means accepting the commands of God and the commandment. Islam came as an achievement for all the heavenly religions. Before building Islam and mosques, the Kaaba was the first house to accept Adam's repentance and the place of worship and prayer. Its wall was a crust with a door open to the inside. Its shape was a simple cube (the most organized form with "equal and equal" surfaces to ensure human comfort and stillness)[1][2].

As a simple, four-faced, cubic building, the Kaaba is the metaphorical core and literal focal point of Islam. A lack of decoration on the neutral, earth-toned surface adds to the unassuming air of this building, though its implication is far from that.

In essence, it embodies all that is Islamic simple, pure, and non-changing. It acts as a central focus point for the entire Islamic community. Unity is significant within the faith since every follower must bow to the same single zenith, bringing everyone together regardless of the distance between them [3].

The Kaaba was re-dedicated as an Islamic house of worship, and henceforth, the annual pilgrimage was to be a muslim rite, the Hajj [4][5]. Its four faces apply to the four human faces and the purity of his soul. The vacuum created by the existence of the Kaaba is a revival of the constant feeling of God's presence in the human soul [6] [1] [7].

Human mostly feels confused and emotioned when they surround the outskirts of Kaaba. During Hajj, pilgrims participate in the completion of the Tawaf circle to achieve integration, homogeneity, disposal of additives, repetition, and elements [8].

Many people asked why they have to move that way. All indicate a close connection between the Kaaba and the surrounding area. It is an Islamic order to regulate the path in this space as stated in the Koran and Hadiths and support the theory of the approach of space architecture. It is considered by looking at the concepts of architectural space and emotions of humanity.

Some researchers said that psychologically there was an intricate connection between religion, place, identity, and attachment. The location is acknowledged as an essential component of the link [9]. Another researcher said that it is a geometrical shape or pattern which forms the feeling of a sacred place [10]. Kaaba is one of the holy places in this world, 
so the space around it would probably be shaped by the psychological connection of Islam or the geometrical form of itself. It becomes the focus of this research.

Therefore, the questions of this research are: What kind of nature of space is formed by the existence of the Kaaba? What are the characteristics of the geometric shape of the Kaaba and its role in the formation of this space? What kind of feelings are generated in the human soul and inspired by the spiritual space of the holy Kaaba?

\section{METHODS}

Some methods were used in this study to be consistent with the research topics. Literatures, scientific articles, and research were used to achieve the rules of research theory that include objectives and definition of the Sacred Mosque and Kaaba building.

The study was done by considering the position of Islamic theoretical and practical wisdom, and using the rational method as used in philosophical texts of Ibn Sina. The acquired sensations and resulting impact on incorporeal space and the effect of Holy Kaaba cubic shape on the spiritual area have been reached a research result.

\section{RESUITAND DISC USSON}

\section{THE "HOLY KAABA" OBJ EC TIVES AND DERNITION: WHY KAABA CAШED BY THIS NAME?}

Kaaba in Al moeen dictionary means any house that has four corners, a room, and a home of GodSacred house. While Alaamid dictionary mentions anything has a cubic shape [11]. The reason for naming Kaaba by this name is because Kaaba is elevated above the ground, and Kaaba in language also means rising. In addition to the fact that Kaaba is a square-shaped, and ancient Arabs used this name for any house with four corners.

Later and in the frequent usage, "The house of God Almighty" singled out by Kaaba, so anywhere Kaaba name stated it refers to the house of God Almighty. In the Holy Quran, the word Kaaba came naturally alone in some verses, as it is mentioned in alMaidah 95 [12]:

"O you who believe! Kill not the game while you are in a state of Ihrâm [for Hajj or Umrah (pilgrimage)], and whosoever of you kills it intentionally, the penalty is an offering, brought to the Kabah, of an eatable animal (i.e. sheep, goat, cow) equivalent to the one he killed, as adjudged by two just men among you; or, for expiation, he should feed Masâkîn (poor persons), or its equivalent in Saum (fasting), that he may taste the heaviness (punishment) of his deed. Allâh has forgiven what is past, but whosoever commits it again, Allâh will take retribution from him. And Allâh is All-Mighty, All -Able of Retribution."

The sentence is combined with "the sacred house" word in another verse (al-Maidah 97) [12]: "Allâh has made the Kabah, the Sacred House, an asylum of security and benefits (e.g., Hajj and Umrah) for mankind, and also the Sacred Month and the animals of offerings and the garlanded (people or animals marked with the garlands on their necks made from the outer part of the stem of the Makkah trees for their security), that you may know that Allâh has knowledge of all that is in the heavens and all that is in the earth and that Allâh is the AllKnower of each and everything."

"The house" was also called on holy Kaaba in another verse (al-Anfal 35) [12]:

"Their Salât (prayer) at the House (of Allâh, i.e., the Kabah at Makkah) was nothing but whistling and clapping of hands. Therefore taste the punishment because you used to disbelieve."

“Al-Masjid-Al-Harâm” also called on holy Kaaba in al-Baqarah 149 [12]:

"And from wheresoever, you start forth (for prayers), turn your face in the direction of AlMasjid-Al-Harâm (at Makkah), that is indeed the truth from your Lord. And Allâh is not unaware of what you do."

\section{THE SACRED MOSQUE AND KAABA BUIDING}

Kaaba is a building at the center of Islam's most sacred mosque; Al-Masjid al-Haram, in Mecca, al-Hejaz, Saudi Arabia. It is the holiest The sanctuary around Kaaba is called Al-Masjid al-Haram (Sacred Mosque). Kaaba is a cube structure that is made of granite. Kaaba is approximately $13.1 \mathrm{~m}$ (43 ft) high, with sides measuring $11.03 \mathrm{~m}(36.2 \mathrm{ft})$ by $12.86 \mathrm{~m}(42.2 \mathrm{ft})$. Inside Kaaba, the floor is made of marble and limestone. The

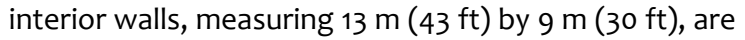
clad with tiled, white marble halfway to the roof, with darker trimmings along the floor.

The floor of the interior stands about $2.2 \mathrm{~m}$ (7.2 $\mathrm{ft}$ ) above the ground area where tawaf is performed. The wall, directly adjacent to the entrance of Kaaba, has six tablets inlaid with inscriptions, and there are several more tablets along the other walls. Along the top corners of the walls runs a green cloth embroidered with gold Quranic verses. Caretakers anoint the marble cladding with the same scented oil used to anoint the Black Stone outside. Three pillars stand inside Kaaba, with a small altar or table set between one and the other two.

Lamp-like objects (possible lanterns or crucible censers) hang from the ceiling. The ceiling itself is of a darker color, similar in hue to the lower trimming. A golden door-(Babut Taubah meaning "Door of Repentance") - on the right wall (right of the entrance) opens to an enclosed staircase that leads to a hatch, which itself opens to the roof. Both the roof and ceiling are made of stainless steel-capped teak wood [4] [13]. This explanation can be seen in Figure 1. 


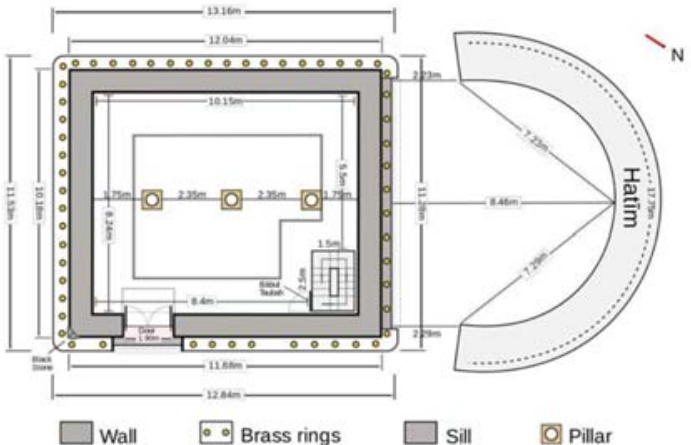

Figure 1. A technical drawing of Kaaba showing dimensions and element

Each numbered item in the following list corresponds to features noted in the diagram image.

1. Al-Hajaru al-Aswad (the Black Stone) is located on Kaaba's eastern corner. Its northern edge is known as the Ruknu l-Īrāqi (the Iraqi corner), its western as the Ruknu sh-Shāmì (the Levantine corner), and its southern as Ruknu I-Yamani (the Yemeni corner). The four corners of Kaaba roughly point toward the four cardinal directions of the compass. Its major (long) axis is aligned with the rising of the star Canopus toward which its southern wall is directed, while its minor axis (its east-west facades) roughly align with the sunrise of the summer solstice and the sunset of the winter solstice.

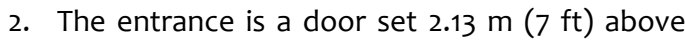
the ground on the north-eastern wall of Kaaba, which acts as the façade.

3. Meezab-i Rahmat is a rainwater spout made of gold; added in the rebuilding of 1627 after the previous year's rain caused three of the four walls to collapse.

4. Gutter, added in 1627 to protect the foundation from groundwater.

5. Hatim (also romanized as hateem) is a low wall originally part of Kaaba [14]. It is a semi-circular wall opposite, but not connected to, the northwest wall of Kaaba. It is $90 \mathrm{~cm}$ (35 in) in height and $1.5 \mathrm{~m}(4.9 \mathrm{ft})$ in width and is composed of white marble. At one time the space lying between the hatim and Kaaba belonged to Kaaba itself, and for this reason, it cannot be entered during the tawaf.

6. Al-Multazam is the roughly 2-meter space along the wall between the Black Stone and the entry door [14]. It is sometimes considered pious or desirable for a pilgrim to touch this area of Kaaba, or perform dua prayer there.

7. The Station of Abraham (Maqam Ibrahim) is a glass and a metal enclosure with what is said to be an imprint of Abraham's feet. Abraham is said to have stood on this stone during the construction of the upper parts of Kaaba, raising Ismail on his shoulders for the uppermost portions.

8. Corner of the Black Stone (East).

9. Corner of Yemen (South-West). Pilgrims traditionally acknowledge a sizeable vertical stone that forms this corner.

10. Corner of Syria (North-West).

11. Corner of Iraq (North-East). This inside corner, behind a curtain, contains Babut Taubah (Door of Repentance) that leads to a staircase to the roof.

12. Kiswah (the embroidered covering) is a black silk and gold curtain that is replaced annually during the Hajj pilgrimage. Two-thirds of the way up is a band of gold-embroidered Quranic text, including the Shahada (the Islamic declaration of faith).

13. Marble stripe is marking the beginning and end of each circumambulation. [Figure 2]

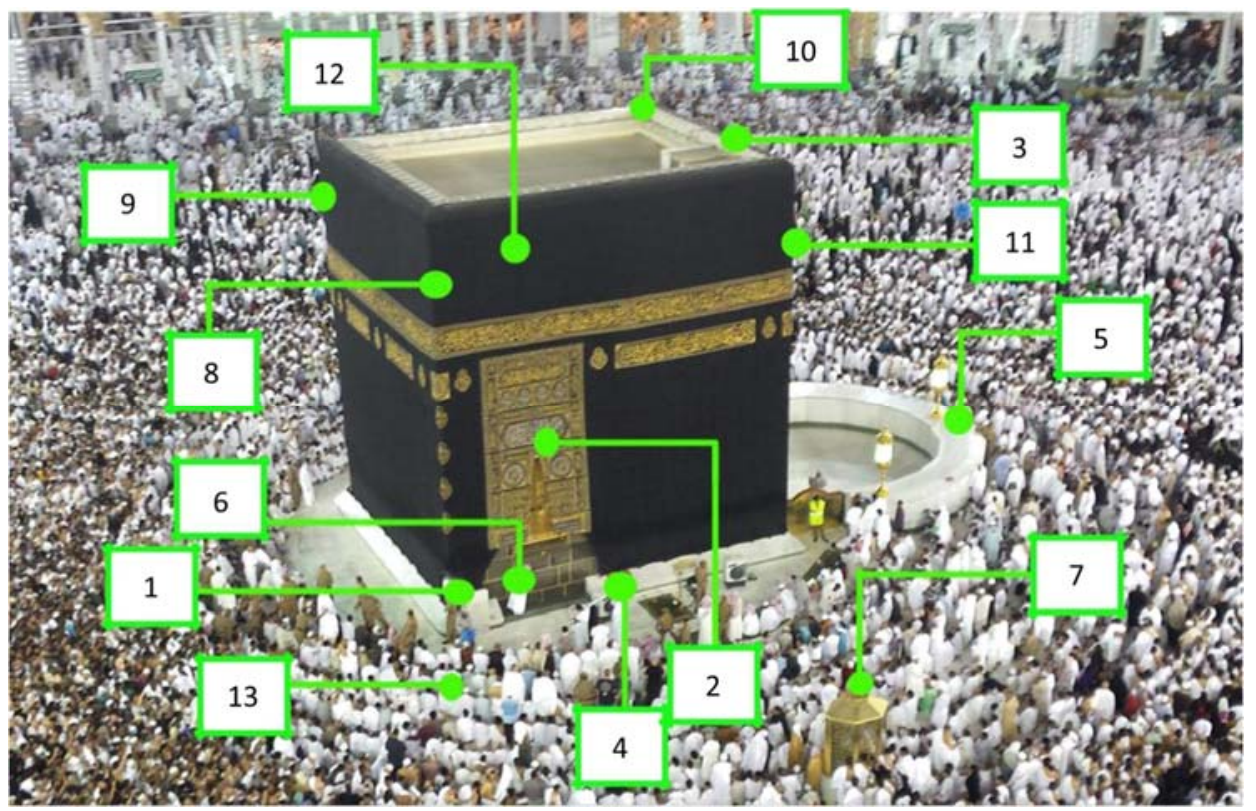

Figure 2. the Element of Kaaba 


\section{THE GEOMEIRIC SHAPE OF KAABA}

Kaaba is a cubic-shape building and has six square surfaces because it is near to the houses in square-shaped. Why they formed in the square shape is because there are four words in Islam: glory is to God, praise is to God, there is no god but God, and God is the greatest [14]. The overall shape of Kaaba is composed of six faces: top, bottom, and the four directions. Or as three original axes: length, width, and height, where these six faces are consist of three surfaces each one corresponds with a parallel surface and completely applies to it. In turn, these faces represent the three main axes, which also converge in central point that is the weight of the whole world and the appearance of celestial appearances [14]. [Figure 3]
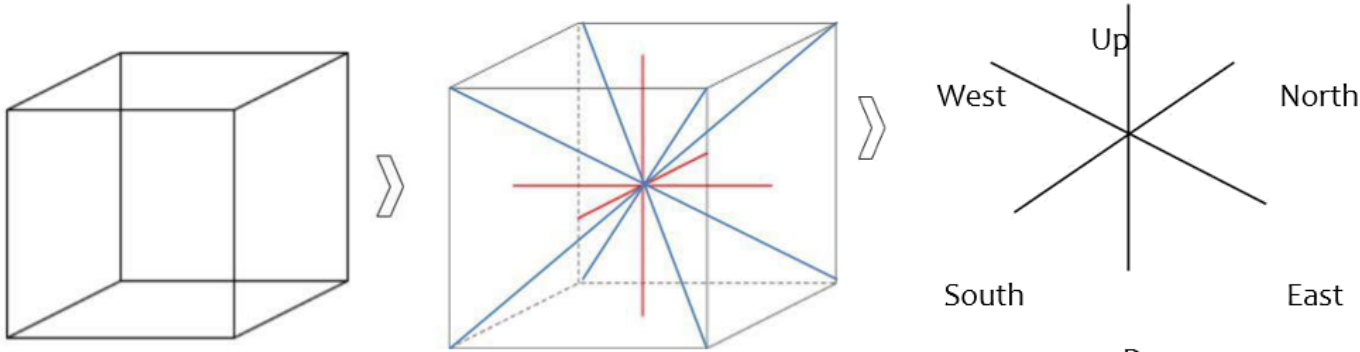

South

East

Do

Figure 3. The geometric shape of Kaaba

Virtual characteristics of Kaaba shape:

- Equalizer: arising from Justice. Cubic shape with various trends gives the viewer a sense of stability and also quantitative, mathematical and physical strength.

- Symmetry: holy Kaaba has a visible symmetric shape.

- Simplicity: cubic is the simplest known shape, making human feels poverty in front of the richness of the homeowner; i.e., spiritual sense - which does not need such a complexity in form and ratios to be shown.

- Balance: optical balance appears thoroughly in all Kaaba faces, except the northwest face due to the presence of black stone which brings a higher number of chaperones around it. The thing that ostensibly breaks the optical balance, but at the same time, reminds human of holy

- Kaaba entry method and that the black stone is from paradise. While "Hejer Ismail" at the other side of holy Kaaba restores balance by gathering chaperones to pray near it.

- Unity: The most important beauty assets; unity of life, afterlife, the oneness of the Creator, unity of shapes despite its plentiful, uniformity of the Islamic nation, and unity of humanity along the time [15].

\section{KAABA ON EARTH IS A SYMBOL OF THE CREATOR OFTHE WORLD}

Kaaba is a simple cube because God Almighty has neither shape, nor color, nor any similar. Any design or any shape that can leap to mind is not God almighty. God is absolute without any direction. We can show "no direction" in the earth only in the following way; collecting all contradictory directions with each other to make each direction negates its opposite. In that state, the mind will be oriented to "no direction". Cube is the only shape that combines the six directions and represents them all. All directions mean non-determination of specific direction.

"And to Allâh belong the east and the west, so wherever you turn (yourselves or your faces), there is the Face of Allâh (and He is High above, over His Throne)". (Al-Baqarah: 115) [12].

Furthermore, the straight line also has its willingness and susceptibility to the guidance and integration. As such, square shape which is formed from a set of straight lines - also has the awareness to guidance, integration, and switching to circle. The circle is the closest thing to visualize the absolute. It emanated from one point and started to multiply. During Hajj, pilgrims participate in the process of completing the circle of Tawaf to reach integration, homogeneity, and getting rid of additives, redundancy, and corners. The circle is the symbol of the psyche and a statement of psychological safety from its whole aspects, including the relationship between human and nature. The circle is the symbol of protection; such as owning a ring, necklace, belt, circle of life and death, influx and flowing [16].

\section{THE OBJECTIVES AND DEANIION OF EXISTING APPROACHES OF “INCORPOREALSPACE”}

Architectural space can be defined through different views. There are two ways in thinking and architectural space approach:

1- Studies and researches based on threedimensional geometry basis. In these studies, which conducted using the absolute geometric method, space was considered as a system combines human's relationship with surroundings.

2- Studies and opinions according to psychology (consider space as a field of perceptual). By the closer look on architectural space and human emotions concepts in these studies, the human role gives greater importance. In these studies also, space was defined as one of the human existence dimensions 
[17]. Choosing the fact that the holy Kaaba space is empty of things indicates that the Creator is far above finitude, and evidence of his presence in all places. It also shows that the Creator is far above materialistic and incarnation. The matter that raises in the human soul, the divine light which removes the covers and allows divine light to radiate from the heart. Each space has particular characteristics: Substance, shape, and dimensions; Properties are resulting from form, substance, sizes, and space proportionality, which all leave an impact in the human mind; Incorporeal properties, which regenerate particular values since its being influenced by the global visions, community culture, and design methods.

Human understanding of space is related to his understanding level of himself and surroundings. Taking advantage of a particular area leads to convergence between personal thinking style of the individual, and thinking style generated from space usage, things that make human closer to knowing the space fact.

\section{KAABA INCORPOREAL SPACE, THE COSMIC SECRET} OF SQUARING THE CIRCLE

Square like a circle always had symbolic value too; the number four expresses four directions of the sky and also four seasons of a year. For this reason, it is considered as a cosmic number. Symbolic content of number four is something very ancient that has found a way to Christianity: The four gospels, and four blades of the cross. According to the shape of the cross, we can see that number four has affected on religious architecture of the west and through this way has affected the entire architecture, at least til Renaissance period. Unlike a circle, the square has two directions; the direction of two symmetry axes of the shape or the direction of its diameters. However, none of these directions dominates the other one [18].

Kaaba space is formed from two geometric shapes: square or cube (Kaaba building himself) and circle (circular Tawaf area around holy Kaaba). Inevitably there are basis and secret for selecting these two geometric forms (square and circle). Architects are trying to uncover it to detect its proportion and aesthetics to use these meanings and concepts in their designs. Kaaba (House of God) is earth center symbol, a generic term for any diagram, chart or geometric pattern that represents the cosmos metaphysically or symbolically.

Kaaba is a center world symbol and concentric circles around it (Tawaf circles) symbolize the sky rotation around this center. Space formed from holy Kaaba presence is qualitative space associated with polar geometry. All of them (triangle, square, and circle) have qualitative geometric, and through understanding them, the human can realize the ideal world to end up with the realization of truth.

Kaaba is formed from each of the squares and circle with its four corners represents the model of mosque building that contains dome, square construction, triangles, angles, and octagon. It was taken from the heavenly model which was derived from the vision of Prophet Muhammad at Maraj night. The symbolic geometric language shows the geometric formation of the universe and the connection between its elements. Geometric shapes refer to the permanent presence of God Almighty. The presence of system in creation world, guides to the most important origin of Islam, the monotheism. Universe creation is based on proportionality and systems. Grandeur and vastness of the universe are manifestations of God's justice. Cube is a symbol of the stability, perfection, and strength. It is associated with the only pole of existence. The circle comprises all shapes and is attributed to the first light or the eternal spirit.

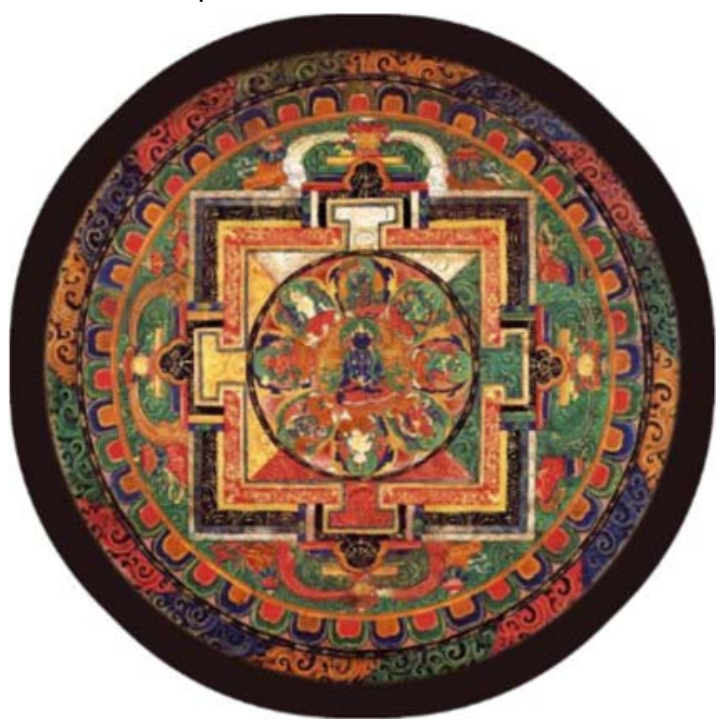

Figure 5. Prajnaparamita Old Mandala

Kaaba is formed from each of the squares and circle with its four corners represents the model of mosque building that contains dome, square construction, triangles, angles, and octagon. It was taken from the heavenly model which was derived from the vision of Prophet Muhammad at Maraj night. The symbolic geometric language shows the geometric formation of the universe and the connection between its elements. Geometric shapes refer to the permanent presence of God Almighty. The presence of system in creation world, guides to the most important origin of Islam, the monotheism. Universe creation is based on proportionality and systems. Grandeur and vastness of the universe are manifestations of God's justice. Cube is a symbol of the stability, perfection, and strength. It is associated with the only pole of existence. The circle comprises all shapes and is attributed to the first light or the eternal spirit.

In other words, in the science of cosmic knowledge, the point shows the first symbol refers to creator, the line indicates the second symbol refers to (mind), and the triangle points out the third symbol refers to (soul). The square means the fourth symbol that indicates to four moods, four directions, four quarters of the world, four seasons, and four doors. Moreover, the Cube as a symbol refers to the body, six directions, and six movement that forces bottom, top, 
back, front, right and left [19].

The results of this research that described the link between the Holy Kaaba cubic shape and its incorporeal space are given in the Table 1.

Table 1. The impact of holy Kaaba cubic shape on the incorporeal space (1 of 2 )

\begin{tabular}{lll}
\hline Kaaba cubic shape properties incorporeal space (the acquired sensations) & The resulting impact on \\
\hline Simplicity & Cubic is the simplest known & $\begin{array}{l}\text { Holy Kaaba spiritual space } \\
\text { makes a human feel poor in } \\
\text { front of the richness of } \\
\text { homeowner. }\end{array}$
\end{tabular}

Symmetry

Holy Kaaba has an obvious symmetric shape

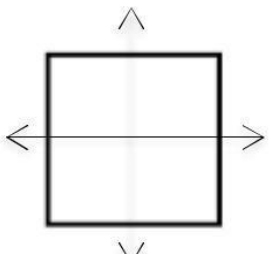

Equalizer

Cubic shape with various trends gives viewer a sense of stability and also quantitative, mathematical and physical strength

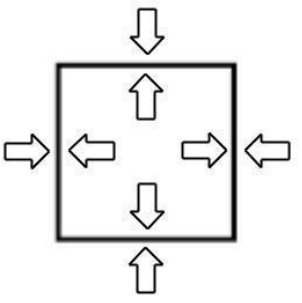

A sense of order and greatness creation, a sense of discipline in human life

The human sense of justice makes human feel absolute submission to God's will and his wisdom.

\begin{tabular}{|c|c|}
\hline \multicolumn{2}{|l|}{ Balance } \\
\hline & $\begin{array}{l}\text { Optical balance appears } \\
\text { thoroughly in all Kaaba faces. }\end{array}$ \\
\hline \multicolumn{2}{|l|}{ Growth potential } \\
\hline & $\begin{array}{l}\text { The most primary shape to } \\
\text { grow out of the condition of } \\
\text { orthogonally } \\
\text { intersecting } \\
\text { perpendicular lines which are } \\
\text { symmetrical about one } \\
\text { another)[20] }\end{array}$ \\
\hline
\end{tabular}

Static form

The form is characterized by four equal sides and four equal angles

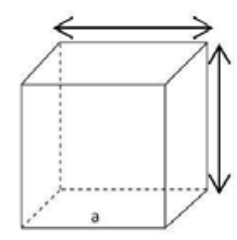

Remind people that they always should have a wise look balanced in their life

The form is characterized by
four equal sides and four
equal angles

108 | Journal of Islamic Architecture, 5(2) Desember 2018 
Table 1. The impact of holy Kaaba cubic shape on the incorporeal space (2 of 2)

Kaaba cubic shape properties incorporeal space (the acquired sensations) The resulting impact on

Affinity between the
circle and the square
Make of using the straight line or curve(circular arc).

Unity
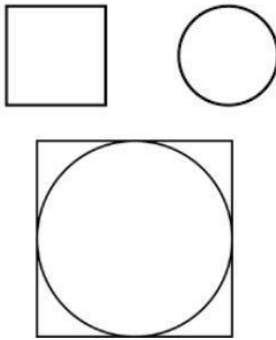

The human can understand the ideal world to end up with the realization of truth

These beauty assets make a human feel beauty. Unity is moving away from the causes of discord and division because there is no difference between humans and preference criterion is their religiousness

look. Also, a sense of peace and sustainability due to a connection felt with God and seeking to reach the perfection that has been formed by the cube-shaped of holy Kaaba.

\section{ACKNOWLDMENT}

The author would like to thank Mr. Hasan Alhawasli for all support and assistance with the publication of this research by providing language help.

\section{REFERENCES}

[1] S. Fatima, "Striving for God's Attention: Gendered Spaces and Piety," Hypatia, A J. Fem. Philos., vol. 31, no. 3, pp. 605-619, 2016.

[2] R. Jamil, "Role of a Dome-Less Mosque in Conserving the Religious and Traditional Values of Muslims: An Innovative Architecture of Shah Faisal Mosque, Islamabad," Int. J. Archit. Eng. Cnstruction, vol. 6, no. 2, pp. 40-45, 2017.

[3] Z. Merod, "Architectural Importance Within the Islamic Tradition," Symposium, vol. 6, no. 2, pp. 48-51, 2017.

[4] A. Imhotep, "Reexamining the Kaaba of Islam," the MOCHA-Versity Institute of Philosophy and Reserch, 2012.

[5] D. A. King, "The Sacred Geography of Islam," in Mathematics and the Design, A Historical Study, T. Koetsier and L. Bergmans, Eds. Elsevier, 2005, pp. 163-178.

[6] J. Herlihy, "The Metaphoric Ascent Of Prayer 
Prayer as Ritual and Intimacy with God," Religions, no. 2, pp. 8-22, 2012.

[7] W. M. K. Shaw, "Between the secular and the sacred a new face for the department of the holy relics at the topkapı palace museum," Mater. Relig. J. Object, Art, Belief, vol. 6, no. 1, 2015.

[8] I. Khan and R. McLeod, "Managing Hajj Crowd Complexity: Superior Throughput, Satisfaction, Health, \& Safety," Kuwait Chapter Arab. J. Bus. Manag. Rev., vol. 2, no. 4, pp. 45-59, 2012.

[9] S. Mazumdar and S. Mazumdar, "Religion and place attachment: A study of sacred places," J. Environ. Psychol., vol. 24, pp. 385-397, 2004.

[10] I. M. T. El-hadidi, "A HOLISTIC APPROACH IN UNDERSTANDING SACRED SPACE," in Sacred Space, pp. 1-12.

[11] D. A. Jannaati, "Names of Kaaba in Holy Quran,” Miqat Hajj J., vol. 1, no. 1, pp. 29-38, 1993.

[12] "King Fahd Complex for the Printing of the Holy Qur'an,” 2016. [Online]. Available: http:// qurancomplex.gov.sa/quran/Targama/ Targama.asp?nSora.
[13] J. M. Bloom and S. S. Blair, Eds., The Grove Encyclopedia of Islamic Art and Architecture. Oxford University press, 2009.

[14] S. Khandra, Upholstered in Mecca and Madina landmarks. Beirut: Dar Al-Hadi Books, 1998.

[15] M. Zadeh, "Kaaba is a beautiful expression and interpretation of being," Fine Arts J., vol. 17, pp. 5-18, 2005.

[16] A. Shariati, Analysis of Hajj rites. Tehran: Elham Publishers, 1984.

[17] A. Vidler, Warped space: art, architecture, and anxiety in modern culture. MIT Press, 2002.

[18] N. Falakian and A. Falakian, "A Survey on Form and Figure in Architecture," Int. Res. J. Appl. Basic Sci., vol. 5, no. 10, pp. 1323-1328, 2013.

[19] F. Akbari and J. Pvrnamy, "Cosmic geometry of Kaaba," in International Congress of Culture and Religious Thought, Qom, Center for Engineering Leadership Council of Public Culture Bushehr Province, 2015, p. 11.

[20] A. Joslin, Inhabiting the square; a geometry for path and space. Exeter, Cambrigde: Massachusetts Institute of Technology, 1982. 